\title{
Translation Strategies Employed by EFL Learners and the Impact of That on Their Translation Skills Development
}

\author{
Abdulkhaleq Q. A. Hassan ${ }^{1}$ \\ ${ }^{1}$ Department of English, College of Science and Arts, King Khalid University, Saudi Arabia \\ Correspondence: Abdulkhaleq Q. A. Hassan, Department of English, College of Science and Arts, King Khalid \\ University, Saudi Arabia. E-mail: abqaseem@kku.edu.sa
}

Received: March 4, 2020

Accepted: April 5, $2020 \quad$ Online Published: April 12, 2020

doi:10.5539/ijel.v10n4p34

URL: https://doi.org/10.5539/ijel.v10n4p34

\begin{abstract}
The present cross-sectional empirical study investigates the different types of strategies and methods that the undergraduate students employ when translating from their native language into the target language and vice versa. The study was conducted on one hundred twenty, third and fourth year, students at the College of Science and Arts, King Khalid University. The data were collected through translation tasks and questionnaires. Both qualitative and quantitative methods were used to analyze and interpret the data collected to achieve the objectives of this study. The study revealed valuable information. The most favored strategies by Arab college students were literal translation, free translation and word-for-word translation respectively. More than half of the all used strategies were literal translation with a percentage of about fifty-five. The mixed translation strategies were found to be about twenty one percent for all the three levels. Free translation strategy was only fourteen percent which is, somehow, a low percentage. The students showed considerable improvement as they progress from one level to a higher one. It is expected that translation instructors as well as course designers will reflect on the findings of this study by raising the learners' awareness of the great differences between English and Arabic when teaching or designing translation courses. Parallel texts that include literal translation as well as free translation have to be included to show the deficiency and ungrammaticality of the texts produced when applying literal translation.
\end{abstract}

Keywords: translation strategies, literal translation, free translation, mixed translation

\section{Introduction}

Communication between people of different tongues and different cultures would not be that easy if there is no translation. So, translation has a pivotal role of bridging the gap between these different tongues and cultures.

Translation is defined almost the same in all dictionaries. It is defined in the Longman Dictionary of American English as 'to change speech or writing from one language to another' (Longman 2008, p. 1067), in the Oxford Dictionary of Current English, to translate is to 'express the sense of (a word, text, etc.) in another language or in another form' (p. 971) and in Webster's Unabridged Dictionary (2016, p. 14098) 'The act of rendering meaning into another language'.

What different scholars such as Nida (1964), Catford (1965), Hatem and Mason (1990), Newmark (2001) believe about translation do not differ much from the definitions mentioned in most of the dictionaries. Besides definitions, these scholars attempted to link the theory of translation to its practice and provided sound and scientific explanations of its process.

For example, Nida $(1964$, p. 12) points out that translation is a process in which the translator attempts to convey the message as accurate and appropriate as that in the source language both in terms of meaning and style. He argues that the cultural differences between the source and the target languages may cause complications for translators more than the linguistic or structural differences can do. So, he suggests that equal emphasis should be given to both the linguistic and cultural aspects of language in the process of translation.

Like Nida, Catford (1965) states that translation is a process in which a text in one language is replaced by another text that has the same meaning in another language. However, Catford (1965) lays more emphasis on the linguistic aspect of the language than on the cultural one.

Similarly, Hatem and Mason (1990) see translation as transferring of the meaning from the source language to the target language. Newmark (2001, p. 7) even went further when he claims that translation is 'a craft' in which the 
written or oral message is replaced by the same message in another language.

Moreover, in the process of translation, many aspects should be taken into consideration such as meaning, structure, style, culture, etc. Bassnett $(1954$, p. 2) states that, when translating a given text from a source language into a target language, translators have to consider both the structure and the meaning. She continues to say that, translators should make sure that the surface meaning of the two languages will be as similar as possible. Brislin (1976) also claims that translation is not merely transferring of meaning, but it means transferring of thoughts and ideas from the source language to the target language, whether written or oral, whether they have established orthographies or not and whether they are based on signs or not.

Nida (1964) and Kholosi (1986), on the other hand, state that the meanings of words are not fixed but they might be changed since they are not dead words. To them, the text's spirit, the words and the structures enjoy the same importance.

Ghazala (1995) asserts that translation includes both the processes as well as the methods used by translators to convey the meaning. He rightly states that for an accurate and appropriate translation, translators have to fully understand the meaning of source text. According to him, all aspects of language such as meaning, grammar, style and sounds enjoy the same importance in the process of translation where failing to observe any one of them will lead to distorting of meaning.

\subsection{Translation Strategies and Methods}

Newmark (1988, p. 45) mentioned eight different types of translation strategies according to whether the emphasis is given by the translators to the target language or to the source language.

\section{SL emphasis \\ 1. Word-for-word translation \\ 2. Literal translation \\ 3. Faithful translation \\ 4. Semantic translation}

\section{TL emphasis \\ 1. Adaptation \\ 2. Free translation \\ 3. Idiomatic translation \\ 4. Communicative translation}

Word-for-word translation, according to Newmark, is a kind of 'interlinear translation' in which the target language words are placed under the source language words. Literal translation, on the other hand, means that the source language words are translated to their nearest equivalence in the target language including structure. In 'faithful translation', the translator tries his/her best to retain the exact contextual meaning of the original text. 'Semantic' translation is similar to 'faithful translation' except for laying more emphasis on showing the beauty and naturalness of the sounds of the source language text.

The first strategy of these target language oriented, that is, adaptation, according to Newmark, is the 'freest form of translation'. This strategy is used for translating literary texts such as plays and poetry in which themes, characters and plots are unchanged. Free translation, on the other hand, focuses mainly on the content or the message irrespective of the form of the original text.

In 'communicative translation' the translators attempt to retain the exact contextual meaning of the original texts in which both the content and the language are acceptable and understood by the readers.

Newmark goes on to say that, among all the strategies mentioned, 'only semantic and communicative translation fulfil the two main aims of translation, which are first, accuracy, and second, economy.'

However, Jakobson (2000, p. 114) identified three different types of strategies of translation: 'Intralingual, interlingual and inter-semiotic translation'. According to him 'Intra-lingual translation or rewording' means interpreting verbal signs by other signs in the same language; 'Inter-lingual translation' means interpreting verbal signs by signs in some other language whereas 'Inter-semiotic translation' means interpreting verbal signs by nonverbal sign systems.

Dickens et al. (2002, p. 29), on the other hand, listed some practical and useful translation strategies that might help translators handle their culturally bound texts properly and accurately. To them, translation is not just about the meaning in both the languages, the source language and the target language, but rather about the culture. They provided four types and degrees of cultural transposition as follows:

1) exoticism and calque

2) cultural borrowing 
3) communicative translation,

4) cultural transplantation.

According to Dickens et al, the first type, i.e. exoticism and calque, is oriented towards SL whereas the third type, i.e., communicative translation, is directed towards TL. The second and the fourth types, on the other, hand are less oriented. Dickens et al. (2002) also used two terms to refer to translation strategies which are 'translating by a hyponym' and 'translation by a hyperonym'. According to them, in the former, the target word has a narrower or a more specific meaning than the original word in the source text whereas in the latter, the target word has a more general or wider meaning than the original word in the source text.

Another two translation types or strategies were identified by Nord (1991 and 2005) which he called 'documentary translation' and 'instrumental translation'. The first one which includes, according to him, word for word translation, literary translation, philological translation and exoticizing translation 'serves as a document of a source culture communication between the author and the source text receiver.' The second type, on the other hand, is instrumental in the sense that the message is conveyed directly from the source text translator to the target language recipient.

Nord (2005) went even further to claim that the instrumental translation has three different types which are:

1) "equifunctional translation" where the target text achieves or serves the same function and the same purpose as that of the source text.

2) "Heterofunctional translation" which occurs, according to Nord, when the purpose of a source language text is not easily recognized or understood by the receiver of the target text. Here, the translator has to adjust it in a way that it does not violate the norms of the source language text.

3) "homologous translation" which is mainly employed in the translation of poetic and literary texts. In this type of translation, according to Nord, the translator attempts to maintain the same effect of the source language through repeating or imitating source text function.

\subsection{Questions of the Study}

This study tries to answer the following questions:

1) What is the most frequent translation strategy used by college students?

2) Are there any differences in translation strategies used by students of different levels?

3) What is the impact of these translation strategies on the development of students' translation skills?

\section{Literature Review}

Dweik and Abu-Shakra (2010) did a study to investigate the translation strategies used by students when translating lexical and semantic collocations taken from the Quran, the Hadith and the Bible. This study showed that different strategies were used by these students. The study also revealed that the strategy of synonymy was more frequent when translating lexical collocations whereas literal translation was more frequent strategy when translating semantic collocations in the Holy Quran and in the Bible. Deletion, on the other hand, was the most used strategy in translating collocation in the Hadith.

Similary, Al-Shawi and Tengku (2012) conducted a study to find out the strategies used by translators when translating idioms from Arabic into English and vice versa. Their study revealed that using the strategy of a parallel idiom in the target language was the most common one. They also found that these translators used equivalent meaning strategy but with a different form.

A year later, Salim and Mohammed (2013) also conducted a study to examine the different translation strategies employed when translating the color idiomatic expressions in Naguib Mahfouz's Novel "The Thief and the Dogs" and also to find out the similarities and differences between the meaning in both languages. The study revealed that the translator used four translation strategies for rendering the color idiomatic expressions which are: 'translation of Arabic color idiomatic expression by using an idiom of similar meaning and form of English language idiom, translation by cultural substitution, translation by paraphrasing and translation by omission.'

Moreover, Obeidat (2015) did a study to investigate the English-Arabic translations strategies used on some websites of baby care products. He adopted the framework of skopos theory as a base for his study. The study showed that the most frequent strategy was transference with percentage of almost fifty-six. The second most frequent strategy was transliteration with a percentage of twenty-four. The third most used strategy was literal translation with nearly eleven percent. The last and least frequent method was omission. 
Similarly, Tabrizi and Mahshid (2015) conducted a study to explore the strategies used in the translation of a special technical book, Biomass Gasification \& Pyrolysis (Practical Design and Theory). Their study showed that 'loan translation' was the most frequent strategies with a percentage of about sixty-nine. The researchers commented on this saying that 'the loan translation obviously is not only the easiest and best but also the most discretionary option.' They went on to say that, adopting this strategy is not always the right choice for translators as it might lead to inaccurate and unacceptable texts in the target language. Other strategies reported by them and which were less common were target language equivalents and transliteration.

In addition to the aforementioned studies, Sarah (2016) in her study titled Strategies in the translation of Arabic Da'wah texts: A case study of 'Don't be Sad', tried to investigate the translation strategies used when translating the book titled 'Don't Be Sad', and the degree in which these strategies led to cultural loss. The study found that the translator used eight different translation strategies as to maintain the same effect of the original text in which literal translation was the most frequent one. The second one was translation by omission followed by transliteration. The other five strategies were translation by addition, translation by definition, cultural transplantation generalization, and particularizing.

Nazzal (2016) also conducted a study to examine the translation strategies adopted by the translator when translating the book I Saw Ramallah by the Palestinian writer Mourid Barghthouti. Moreover, the study tried to explore the problems that the translator encountered when dealing with culturally bound expressions in this book. The findings revealed that the translator used various translation strategies to render the meaning from the source language to the target language such as omission (words omission, phrases omission, and whole paragraph omission), dialect standard English rendering, multiple translations for one word, Arabic dialect standard English rendering.

Equally, Alshammari (2016) did a research to investigate the translation strategies used in translating English similes found in Ernest Hemingway's novel 'The Old Man and The Sea'. The researcher followed Pierini's model. The study showed that literal translation was the most prominent strategy used in rendering English similes to Arabic.

Another study was conducted by Amina (2017) to identify the strategies utilized when translating English advertisement slogans into Arabic in which the findings showed that free translation was the most frequent strategy used by translators when translating the English advertisements slogans followed by literal translation, which according to him, was as effective and accurate as those of the original. Other strategies reported in this study were adaptation, equivalence, and modulation.

A most recent study was done by Al-adwa and Mamon (2019) in which they attempted to identify the strategies and shifts that translators employ when translating semantic repetition, which according to them, is more common in Arabic literature than in English. They collected the data from the modern Arabic short story Excerpt from The Book of The Dead and its English translation. The researchers found that four translation strategies were used by the translators when handling semantic repetition which are: 'retention, compression, grammatical shift and deletion.' The retention strategy was the most frequent and most preferable by these translators whereas the other three strategies were less common.

\section{Methodology}

In this part, the researcher will explain the methods which he used to achieve the objectives of his study such as the subjects who were involved, the data collection and the data analysis.

\subsection{Participants}

The subjects for the present study were one hundred twenty, third and fourth-year male (due to the fact of gender segregation in Saudi universities) students, who were studying English as a foreign language at the Department of English, College of Sciences and Arts, King Khalid University in Saudi Arabia. They have the same mother tongue, i.e. Arabic. They almost have the same background. In the English program of the Department of English, students have to fulfill the requirements of getting a bachelor degree by completing one hundred twenty hours fourteen of them are requirements courses like Islamic culture, Arabic language and introduction to computer. The remaining one hundred six hours are all English courses. Six credit hours are assigned to three translation courses, i.e., two credit hours each. Translation I, in level six (second semester of the third year), Translation II, in level seven, and Translation III in level eight with a total of ninety contact hours, i.e., thirty hours per semester for each course. In Translation I, they study theories, methods and techniques of translation in general while in Translation II they practice translating texts of general subjects. In the last level, they take Translation III, which focuses mainly on Islamic text translation. 


\subsection{Data Collection}

The data for this study were collected through two methods: translation tasks and questionnaires. The one hundred twenty students received four translation tasks every month with a total number of 12 tasks in each level. By the end of the semester, the students were given a questionnaire to fill out.

\subsection{Data Analysis and Discussion}

The data of this study, after they were collected, were tallied and analyzed. Microsoft Excel 2019 and SPSSv.24 programs were used to analyze and interpret the data collected. As the size of the data was, to some extent huge, the researcher sought the help of two faculty members to sort out the data taken from the translation tasks. The data collected from the translation tasks from each level were analyzed separately to see whether there were any differences between the methods employed by students of different levels.

Table 1. The strategies employed by level six

\begin{tabular}{lllll}
\hline Strategy used & Frequency & Percent & Valid Percent & Cumulative Percent \\
\hline Word for Word Translation & 66 & 13.8 & 13.8 & 13.8 \\
Literal Translation & 302 & 62.9 & 62.9 & 76.7 \\
Free Translation & 18 & 3.8 & 3.8 & 80.4 \\
Mixed Translation & 94 & 19.6 & 19.6 & 100.0 \\
Total & 480 & 100.0 & 100.0 & \\
\hline
\end{tabular}

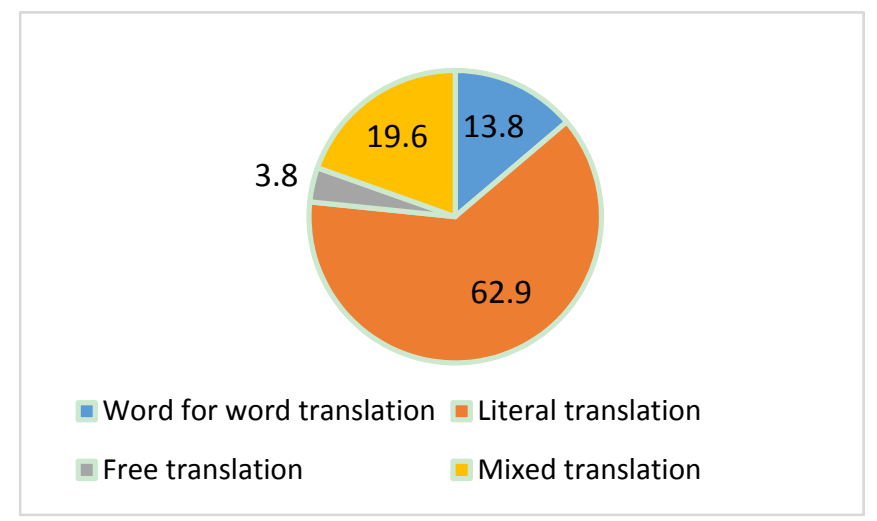

Figure 1. Percentages of strategies used by level six students

Table 1 and Figure 1 show the frequencies and distributions of translation strategies employed by level six students. As this was the first course of translation for them, their dependence on the system of their mother tongue, i.e. Arabic, seems to be clear. They adopted literal translation as the main strategy in rendering the meaning. The results show that the percentage of literal translation was almost sixty-three which is high and above average. The students used the structure of their mother tongue to a great extent. The following examples show how the students are not aware of the differences between the two languages, their mother tongue and the target language.

1) *went Ahmed to makka for do umrah and then went to almadina.

(Ahmed went to Mecca for Umrah, and then he went to Medina.)

2) *The Muslim who safe the muslims from his tongue and his hand.

(A Muslim is the one from whose tongue and hands the Muslims are safe.)

3) *His father sick angry very from him.

(His father is very angry with him.)

In example 1, the students translated the Arabic sentence هب احمد إلى مكة لأداء العمرة ومن ثم ذهب إلى المدينة.

as (*went Ahmed to makka for do umrah and then went to almadina) where they started the sentence, as in Arabic, with a verb, they used a definite article for 'medina' as in Arabic. In example 2, المسلم من سلم المسلمون من لسانه ويده translated literally as '*The Muslim who safe the muslims from his tongue and his hand'. They used a wrong article, where it is not applicable in English, just like in Arabic (almadinah *the madian) and they did not use linking verb 
as linking verbs are not available in Arabic, repetition of reflexive pronouns as in Arabic. In example 3, والده زعلان جـا منه His father angry very from him.), is also atypical example of literal translation strategy as there is no linking verb as in Arabic, the degree adverb modifiers come after the adjectives, likewise, the adjectives mostly come after the nouns they modify, unlike English which come before.

The second most frequent strategy was mixed translation strategy with a percentage of about twenty percent. The students in this strategy did use only one particular strategy for most of the text but used more than one such as literal, free translation, omission and transliteration.

The third most common strategy for level six students was the word-for -word translation. In this strategy, as mentioned earlier, the students wrote the translated words exactly above or below the words of the source language. It worth noting here that there are much similarities between literal translation and word-for -word translation.

\section{(YASKUN ALASIRI MA'AA WALIDAYH IN ABHA بسكن العسيري مع واللديه في ابها (W. )}

* lives alasiri with his parents in Abha (Word-for-word translation)

*Live alasiri live in abha with his parents.

*Alasiri live with his parents in Abha. Literal translation

The last and least frequent strategy employed by level six students to render the meaning from the source language to the target language was free translation with as low as about four percent. Although, these students studied English for about three years but their translation abilities are below average when they free translate.

Table 2. The strategies employed by level seven

\begin{tabular}{lllll}
\hline Strategy used & Frequency & Percent & Valid Percent & Cumulative Percent \\
\hline Word for Word Translation & 53 & 11.0 & 11.0 & 11.0 \\
Literal Translation & 268 & 55.8 & 55.8 & 66.9 \\
Free Translation & 45 & 9.4 & 9.4 & 76.3 \\
Mixed Translation & 114 & 23.8 & 23.8 & 100.0 \\
Total & 480 & 100.0 & 100.0 & \\
\hline
\end{tabular}

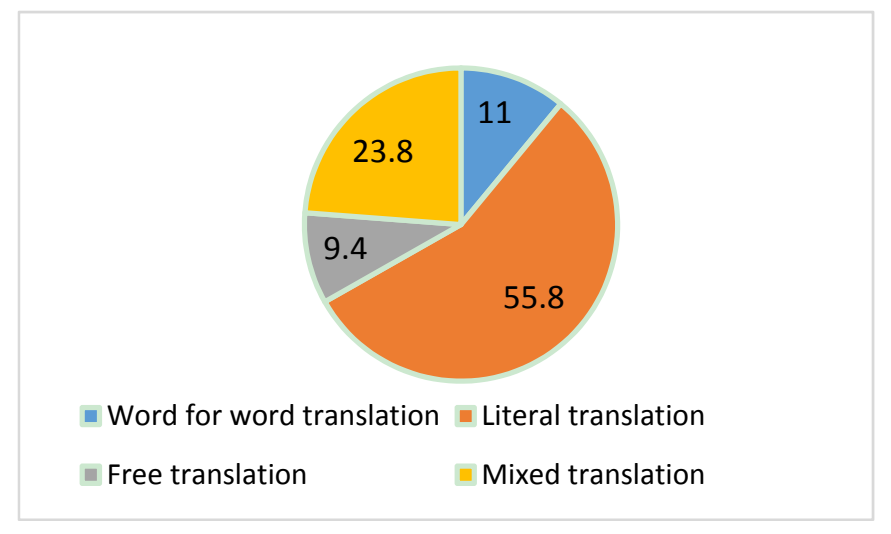

Figure 2. Percentages of strategies used by level seven students

For level seven, again, as in level six, the literal translation strategy emerged to be the most frequent one used for conveying the meaning in the target language with a slight decrease in percentage from level six. Almost fifty-six percent of strategies used was of literal translation which is still, to some extent, high. Mixed translation strategies came second with a percentage of about twenty-four. Again, as in level six, the students used mixed strategies for handling each text. Transliteration was used for many religious terms where the students were not able to find equivalent meaning in the target language and particularly when translating from Arabic to English. Surprisingly, the students of this level used word-for-word translation strategy more than the free translation strategies in which percentages were about eleven and nine respectively. The examples of literal translation and word-for-word translation don not differ much from the examples of level six students that are mentioned above. 
Table 3. The strategies employed by level eight

\begin{tabular}{lllll}
\hline Strategy used & Frequency & Percent & Valid Percent & Cumulative Percent \\
\hline Word for Word Translation & 27 & 5.6 & 5.6 & 5.6 \\
Literal Translation & 215 & 44.8 & 44.8 & 50.4 \\
Free Translation & 139 & 29.0 & 29.0 & 79.4 \\
Mixed Translation & 99 & 20.6 & 20.6 & 100.0 \\
Total & 480 & 100.0 & 100.0 & \\
\hline
\end{tabular}

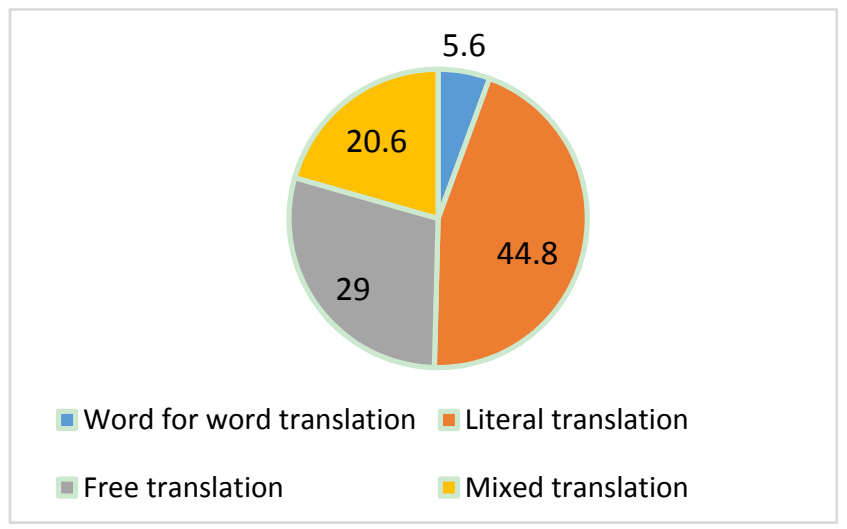

Figure 3. Percentages of strategies used by level eight students

Table 3 and Figure 3 show the frequencies of translation strategies used by level eight students, the last level in the BA program. The results show that there was a slight improvement in performance. The students' dependency on literal translation came down from about sixty-three in level six to about forty-five percent and this, in fact, is still high. Literal translation in most of the cases, and especially when the gap between Arabic and English is big, leads to ungrammatical and inaccurate texts in the target language. The students showed some progress in using free translation strategy which increased from only about four percent in level six to about twenty-nine percent in level eight. As for mixed translation, the percentage was about twenty one percent which does not differ much from that of level six. The word-for-word translation strategy was the least common for level eight students with a percentage of about six.

Table 4. The frequencies and percentages of strategies employed by students of the three levels

\begin{tabular}{lllll}
\hline Strategy used 6 & Frequency & Percent & Valid Percent & Cumulative Percent \\
\hline Word for Word Translation & 146 & 10.14 & 10.14 & 10.14 \\
Literal Translation & 785 & 54.51 & 54.51 & 64.65 \\
Free Translation & 202 & 14.0 & 14.0 & 78.7 \\
Mixed Translation & 307 & 21.32 & 21.31 & 100.0 \\
Total & 1440 & 100.0 & 10.14 & \\
\hline
\end{tabular}

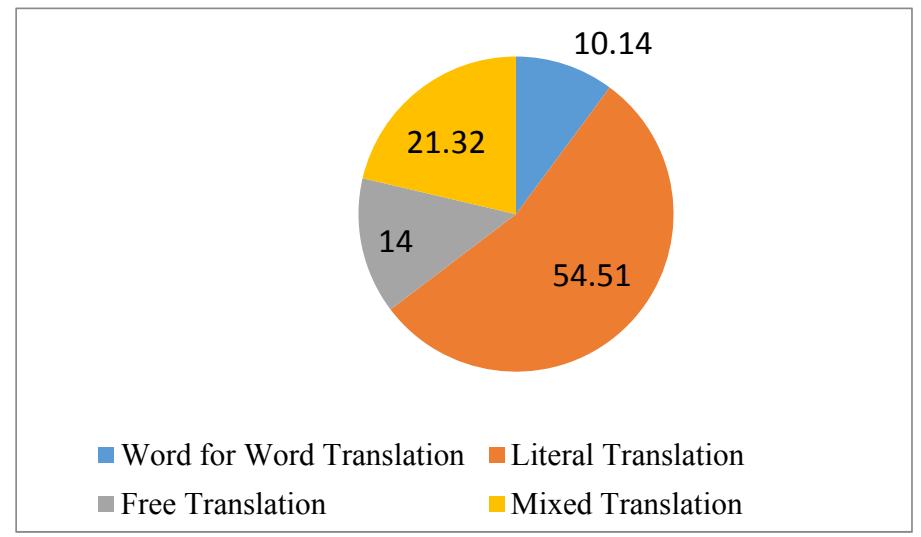

Figure 4. Percentages of strategies used by the students of the three levels 
Table 4 and Figure 4 show the overall frequencies and percentages of the strategies used by the one hundred twenty students of the three levels, level 6, level 7 and level 8 of the BA program at the Department of English, college of Science and Arts, who participated in the study. As it was hypothesized, literal translation was the most frequent translation strategy in all the three levels as it was found to be almost fifty-five percent. The study shows that as the students make some progress in their study and move to a higher level, the percentages of literal translation deceased and, in turn, their abilities to free translate increased. The second most common strategy was mixed translation with a percentage of about twenty-one. The third strategy was literal translation with a percentage of about fourteen. The last and least frequent strategy for all the three levels was word-for-word translation with a percentage of about ten.

By analyzing the data taken from the questionnaires distributed to the students, it was found that level six students prefer literal translation strategy more than other strategies and this goes in line with the results of their translation tasks. Level eight, on the other hand, said that they prefer free translation as it frees them from language restriction. Level seven were in between as fifty-five of them said they prefer free translation.

\section{Conclusion}

This study was conducted with the aim of investigating the translation strategies employed by the EFL undergraduate students in different levels at King Khalid University and the impact of that on their translation skills development. The findings of the study showed that, in all the students' translation tasks, literal translation was the most frequent. The degrees of frequencies vary from level to level. In level six, since this was the first course in translation for them, the percentage of using this strategy was high compared to the other two levels. In most of the cases, there was difficulty understanding the translated texts as Arabic and English have quite different systems. The meaning of the texts was almost distorted either in Arabic or in English. The word-for-word translation strategy, when used for translating Arabic text to English leads to distorted structures whereas however when translating from English to Arabic may be correct as Arabic sentences can start with either verbs, in verbal sentences, or with nouns, in nominal sentences. It is expected that the findings of this study will provide insights into translation difficulties of the Arab learners. It may help the translation teachers as well as the courses designers to tackle the problem of adopting literal translation strategy that leads to undesirable and ungrammatical texts. Furthermore, reflecting upon the findings of this study, the translation teachers as well as the courses' designers are recommended to provide parallel texts, in which the source language along with the target language with both literal translation and free translation to make students aware of the differences between the two texts and also to show them the deficiency and ungrammaticality of the texts produced when using literal translation. They are also recommended to have a balance between translation theory and practice when teaching translation courses.

\section{Acknowledgements}

The author is grateful to King Khalid University for providing financial and technical support for this study.

\section{References}

Al-adwan, A., \& Mamon, A. (2019). Handling Semantic Repetition when Translating Arabic Short Stories: The Case of Excerpt from The Book of The Dead. The Southeast Asian Journal of English Language Studies, 25(2), 49-60. https://doi.org/10.17576/3L-2019-2502-04

Al-Shawi, M., \& Tengku, T. (2012). Strategies for Translating Idioms from Arabic into English and Vice Versa. Journal of American Arabic Academy for Sciences and Technology, 3(6), 139-147.

Alajlan, S. (2016). Strategies in the translation of Arabic Da'wah texts: A case study of 'Don't be Sad'. International Journal of Language and Linguistics, 3(5), 144-152.

Allegory, M.-W. (2016). Webster's Unabridged Dictionary.

Alshammari, J. (2016). Analyzing Arabic Translation Methods of English Similes: A Case Study of The Old Man and The Sea by Ernest Hemingway. Theory and Practice in Language Studies, 6(3), 485-494. https://doi.org/10.17507/tpls.0603.05

Amina, A. (2017). Investigating the Strategies Used to Translate English Advertisement Slogans into Arabic. Revue Sciences Humaines, A, 05-16.

Bassnet, S. (1954). Translation Studies. London: Routledge.

Brislin, R. (1976). Translation: Application and Research. New York: Gardner Press Inc.

Catford, J. (1965). A Linguistic Theory of Translation: An Essay in Applied Linguistics. Oxford: Oxford University Press 
Dweik, B., \& Abu-Shakra, M. (2010). Strategies in Translating Collocations in Religious Texts from Arabic into English. Eric, ED510365, 1-38.

Ghazala, H. (2008). Translation as problems and Solutions (Special ed.). Beirut, Lebanon: Dar Elllmi Lilmalay in \& Konooz Al-Marifa

Hatim, B., \& Mason, I. (1990). Discourse and the Translator. New York: Longman.

Jakobson, R. (2000). On Linguistic Aspects of Translation. In V. Lawrence (Ed.), The Translation Studies Reader (pp. 113-118). London and New York: Routledge.

Kholosi, S. (1986). The Art of Translation. Cairo: GEBO.

Longman, P. (2008). Longman Dictionary of American English. Pearson publisher.

Nazzal, A. (2016). The Translation of Mourid Barghthouti's Autobiography as a Cultural Encounter. International Journal of English Linguistics, 8(6), 216-226. https://doi.org/10.5539/ijel.v8n6p216

Newmark, P. (1981). Approaches to Translation. Oxford: Pergamon Press.

Newmark, P. (1982, 2001). Approaches to Translation. Shanghai: Shanghai Foreign Language Education Press.

Newmark, P. (1988). A Textbook of Translation. Prentice Hall International.

Nida, E. (1964). Toward a Science of Translating. Leiden: Brill.

Nida, E., \& Taber, C. (1969). The Theory and Practice of Translation. Leiden: E.J. Brill. https://doi.org/10.2307/411434

Nord, C. (1991). Text analysis in translation: Theory, methodology, and didactic application of a model for translation-oriented text analysis. Amsterdam: Rodopi.

Nord, C. (2005). Text analysis in translation: Theory, methodology, and didactic application of a model for translation-oriented text analysis. Amsterdam: Rodopi.

Obeidat, E. (2015). Translation Strategies in the English-Arabic e-Brochures of Baby Care Products. Jordan Journal of Modern Languages and Literature, 7(2), 59-82.

Salim, J., \& Mehawesh, M. (2013). Color Idiomatic Expressions in Translating of Naguib Mahfouz's Novel 'The Thief and the Dogs': A Case Study. International Journal of English Linguistics, 3(4), 107-116. https://doi.org/10.5539/ijel.v3n4p107

Tabrizi, H., \& Pezeshki, M. (2015). Strategies Used in Translation of Scientific Texts to Cope with Lexical Gaps. Theory and Practice in Language Studies, 5(6), 1173-1178. https://doi.org/10.17507/tpls.0506.07

Thompson, D. (Ed.). (1993). The Oxford Dictionary of Current English. Oxford University Press.

\section{Copyrights}

Copyright for this article is retained by the author, with first publication rights granted to the journal.

This is an open-access article distributed under the terms and conditions of the Creative Commons Attribution license (http://creativecommons.org/licenses/by/4.0/). 